dad de Indiana. Luego fue nombrado en la Universidad del Estado de Illinois, en Normal, y allí se le otorgó el título de Distinguished Professor, reconocido después de su retiro de la docencia como Profesor Emérito.

Juan Orrego-Salas

Universidad de Indiana,

Bloomington, Estados Unidos

jucar@ciswired.com

\title{
Harold Gramatges (1918-2008) y Juan Blanco (1919-2008)
}

En 2008 dos importantes músicos cubanos y amigos de la Revista Musical Chilena nos dejaron en forma definitiva. Fueron éstos los notables compositores Harold Gramatges y Juan Blanco, ambos piezas fundamentales en el desarrollo de la música de la hermana república caribeña, en el siglo XX.

En Santiago de Cuba, en 1918, vio la luz Harold Gramatges y, desde muy temprano, se acercó a la música inducido por su padre, violinista. Radicado posteriormente en La Habana, estudió con los compositores Amadeo Roldán y José Ardévol y formó parte, desde sus inicios, del Grupo Renovación Musical, donde no sólo se dio a conocer como un talentoso compositor, sino, además, como un inteligente ensayista, crítico y conferenciante. En 1942 ganó una beca y viajó a los Estados Unidos de Norteamérica, a Tanglewood, para recibir lecciones de Aaron Copland. Allí conoció a varios creadores relevantes latinoamericanos de su generación, entre los cuales se pueden mencionar al uruguayo Héctor Tosar, el argentino Alberto Ginastera, al mexicano Blas Galindo, al chileno Juan Orrego-Salas y otros, con los que estableció fructíferos nexos. Con el andar del tiempo esta fraternal relación interamericana continuó, se fortaleció y amplió con generaciones posteriores a la suya, por lo que muchos pudimos gozar de su amistad. De regreso en La Habana trabajó sin descanso a favor del desarrollo de la vida musical cubana, cumpliendo tareas en todos sus aspectos, incluidos aquellos que garantizaran el trato del arte como arte y no como mercancía, y que la música, en particular, llegara a todos los sectores de la población, fomentando para ello los cambios que fueran necesarios. Esta posición suya le valió ser perseguido por la dictadura de Batista a finales de la década de 1950 .

Con el triunfo de la revolución, en 1959, Gramatges ocupó diversos cargos de responsabilidad, asegurando así el salto cualitativo en el quehacer musical cubano que se esperaba de la nueva situación político-social que comenzaba a vivir la Isla. Ese mismo año fue nombrado asesor del Departamento de Música de la Dirección General de Cultura, participando desde allí en la reforma de todo el sistema de enseñanza de la música del país y en la creación de la Orquesta Sinfónica Nacional; en 1960 fue designado embajador de Cuba en Francia, cargo que ocupó hasta 1964; desde 1965 hasta 1970 dirigió el Departamento de Música de la Casa de las América, fundando el boletín Música, y a partir de 1970 se transformó en asesor de la Dirección de Música del Consejo Nacional de Cultura. Cuando en 1976 se creó el Instituto Superior de Arte, Gramatges fue llamado de inmediato para incorporarse a su cuerpo académico. Junto con su brillante participación en el ordenamiento institucional de la música cubana, de la docencia, la investigación y difusión musical, el compositor trabajó intensamente en la creación, dejando un voluminoso catálogo con valiosísimas obras, muchas de ellas premiadas, publicadas y grabadas. Se podría sostener que el reconocimiento de su talento creativo culminó al recibir el Premio Iberoamericano de la Música "Tomás Luis de Victoria", en 1996, que se otorgó ese año por primera vez.

En el pueblo de Mariel, en 1919, nació el compositor Juan Blanco. Su formación inicial como músico la obtuvo dentro del ámbito familiar. Durante ese período recibió la influencia de la música popular que practicaban los trabajadores de su entorno en la pequeña localidad donde vivía. En 1935 se trasladó a la capital y allí estudió música formalmente, concluyendo su carrera de composición con José Ardévol, en el Conservatorio Municipal de Música de La Habana. El joven compositor se integró a la Sociedad Cultural Nuestro Tiempo, a la cual también pertenecía Harold Gramatges. Esta Sociedad agrupó a músicos e intelectuales con la finalidad de rescatar los valores culturales del pasado y promover los nuevos. Fue en esa década, la de 1950, cuando Blanco se inclinaba por una 
corriente con tintes nacionalistas, que recibió el Premio de Música del Movimiento Cubano por la Paz, con su obra Cantata de la paz, y el Premio de Música Coral, con Tríptico coral. Estas creaciones no sólo son representativas de un momento específico de la producción de Juan Blanco, también lo son de una característica siempre presente en su obra: la preocupación por los temas de la lucha contra la opresión y a favor de los derechos del hombre. Además de las mencionadas, otras composiciones son ejemplo de lo mismo, como: Imprecasiones por el crimen de Son My (1970); Chile vencerá, en solidaridad con los que luchaban en contra de la dictadura (1975); Música para un joven mártir, homenaje al alfabetizador mártir Conrado Benítez (1975); Ché dice a sus hijos y responden los niños cubanos (1977); 1789-1989, dedicada al bicentenario de la Revolución Francesa (1989), y muchas más.

En 1959, Juan Blanco fue nombrado director de la Banda del Estado Mayor del Ejército Rebelde, tarea que cumplió hasta 1961. También en 1959 conoció a Alejo Carpentier, quien despertó su interés por las vanguardias musicales y por la utilización de medios electroacústicos en la composición musical. Esta posibilidad técnica respondía a las necesidades estéticas de Blanco y lo sacaba de lo que él mismo llamó "un callejón sin salida". Abandonó, por lo tanto, la corriente nacionalista y se sumó al movimiento vanguardista musical cubano; además, el medio sociopolítico empujaba hacia los cambios en todos los ámbitos. En 1961 presentó sus primeras obras de música concreta y electrónica, iniciando un muy exitoso camino como creador. En 1964 ofreció el primer concierto realizado en Cuba de música electrónica y al año siguiente comenzó una serie de trabajos destinados a vincular la música electrónica con la actividad social: desfiles gimnásticos, sonorizaciones al aire libre, espectáculos multimedia, ambientaciones sonoras de exposiciones, monumentos, etc. En 1979 creó el primer laboratorio de música electroacústica de Cuba y más tarde impulsó encuentros internacionales de esa música, de gran significación. Además, fundó y dirigió el Taller de Música Electroacústica del ICAP (Instituto Cubano de Amistad de los Pueblos), donde formó numerosos compositores, siendo la experimentación sonora la línea matriz de esa entidad.

Es un sincero deseo que la muy breve síntesis hecha de la enorme y ejemplar labor realizada por Harold Gramatges y Juan Blanco sirva como un modesto y franco homenaje a dos grandes figuras de la música continental, así como de acicate para que ambos sean recordados permanentemente por quienes luchan en pro del desarrollo de la música americana.

Fernando García Facultad de Artes, Universidad de Chile,

Chile

fgarcia@uchile.cl

\section{Lukas Foss; políglota y explorador (1923-2009)}

Hace seis años, hablando del futuro, Lukas Foss expresó, con su espontaneidad característica, la esperanza de que "la justicia prevaleciera y mi música recibiese su merecida cuota” y, agregó, "creo que una gran parte de ésta es buena”. Este es un sueño que acarrea consigo mismo un creador toda su vida.

Hoy, a menos de dos semanas de yo cumplir 90 años $^{1}$, a los 86, murió Lukas al cabo de una vida activa, rica de experiencias, acompañada por Cornelia, su mujer y dos hijos, tres nietas y muchos colegas a quienes cautivó con su generosidad, sencillez y simpatía. Nació en Berlín y, a los 15 años, emigró con sus padres a Estados Unidos, huyendo del holocausto.

Copland, en alguna oportunidad, describió la obra de Lukas como compositor como "la más original y estimulante en América" y también la de un "saltarín", que transitaba entre todas las soluciones que le proveía la música contemporánea. Para Lukas éstas nunca constituyeron "soluciones" -ni siquiera "estilos"- sino técnicas que él necesitó para expresarse.

La primera de sus creaciones que escuché -esto antes de conocerle- fue la cantata The Prairie, obra basada en un poema de Carl Sandburg, que él consideraba -como otras compuestas antes de

${ }^{1}$ El maestro Juan Orrego-Salas nació el 18 de enero de 1919 (nota del Editor). 